\title{
The effects of erythropoietin on neurogenesis after ischemic stroke
}

\author{
Si-Jia Zhang ${ }^{1,2}$, Yu-Min Luo ${ }^{1,2,3, *}$ and Rong-Liang Wang ${ }^{1,2, *}$ \\ ${ }^{1}$ Institute of Cerebrovascular Disease Research and Department of Neurology, Xuanwu Hospital of Capital Medical University, \\ Beijing, 100053, P. R. China \\ 2 Beijing Geriatric Medical Research Center and Beijing Key Laboratory of Translational Medicine for Cerebrovascular \\ Diseases, Beijing, 100053, P. R. China \\ ${ }^{3}$ Beijing Institute for Brain Disorders, Beijing, 100053, P. R. China \\ *Correspondence: yumin $111 @ c c m u . e d u . c n$ (Yu-Min Luo); wrongliang@163.com (Rong-Liang Wang)
}

DOI: $10.31083 /$ i.jin.2020.03.4

This is an open access article under the CC BY-NC 4.0 license (https://creativecommons.org/licenses/by-nc/4.0/).

Erythropoietin has been researched for its neuroprotective effects in ischemic stroke for over 30 years. Although erythropoietin can cause side effects that need to be controlled, it has been suggested to be effective in enhancing the prognosis of patients who are out of the therapeutic time window and have not received recombinant tissue plasminogen activator therapy. Studies on the mechanism of the function of erythropoietin have shown that it has various protective effects in ischemic brain injury after stroke, including promoting neurogenesis. In this review, we discuss the effects of erythropoietin on neurogenesis after ischemic brain injury and provide references for effective treatments for ischemic stroke, which is one of the leading causes of death worldwide.

\section{Keywords}

Erythropoietin; neurogenesis; ischemic stroke; clinical translation; neurology

\section{Introduction}

Ischemic stroke, due to its suddenness and complexity of symptoms, is a great challenge worldwide. A full understanding of the pathology and recovery process of ischemia/reperfusion (I/R) is still lacking, and this has inspired scientists to develop new therapies. Since the discovery of neurogenesis in the central nervous system of the adult mammalian brain and because neurogenesis after $\mathrm{I} / \mathrm{R}$ is involved in recovery after ischemic injury, neurogenesisrelated therapies have become new possibilities for stroke treatment, for example, intrinsic neurogenesis-promoting factors, such as brain-derived neurotrophic factor (BDNF), nerve growth factor (NGF) and insulin-like growth factor 1 (IGF-1) (Luft et al., 2008; Pin-Barre and Laurin, 2015). Until now, due to the difficulty in translating dosing and targets from animal models to humans, most of those growth factors are not used as therapeutic agents (Chan et al., 2017b).

Erythropoietin (EPO), which is a hematopoietic factor that is mainly secreted by peritubular capillary bed of the kidneys (Fisher et al., 1996) in the renal cortex as part of the intrinsic response to hypoxia, is also produced by several other tissues, including the brain (Anagnostou et al., 1994; Nagai et al., 2001; Wright et al., 2004), and has become one of the most notable potential neuroprotective treatments since the in vivo experiments conducted by Sakanaka et al. (1998) demonstrated for the first time that EPO has a neuroprotective effect in ischemic brain injury.

EPO can reduce ischemic injury in more diverse ways than other promising neuroprotective treatments, such as N-MethylD-aspartic acid (NMDA) antagonists, gamma-aminobutyric acid (GABA) agonists, free radical scavengers and antiapoptotic drugs (Tuttolomondo et al., 2015), including by reducing intracellular calcium accumulation and excitatory neural toxicity (Sakanaka et al., 1998), relieving oxidative stress (Ostrowski and Heinrich, 2018), decreasing apoptosis (Zhao et al., 2015), inhibiting the inflammatory response (Villa et al., 2003), and reducing damage to the blood-brain barrier (Chi et al., 2008). As a variety of interconnected pathways mediates ischemic brain damage, agents such as EPO, which can regulate multiple pathways, are more effective than those that can only target a single pathway. Ehrenreich et al. (2002) showed very early, and for the first time that EPO therapy for stroke is safe and beneficial in human patients.

Moreover, recent additional studies on EPO have suggested that EPO and EPO receptor (EPOR) are necessary for early embryonic neural development (Alnaeeli et al., 2012) and that EPOR contributes to the migration of newly generated neurons during adult neurogenesis (Tsai et al., 2006), which suggests the potential effect of EPO on post-stroke neurogenesis. As mentioned above, endogenous neurogenesis has been regarded as a novel therapeutic method for ischemic stroke. The promoting effect of EPO on neurogenesis endows it with therapeutic capability during both the acute stage and in the long term. In this review, we discuss the role of EPO in the regulation of neurogenesis after ischemic stroke and its possible mechanism.

\section{EPO and its downstream pathways}

EPO is a $30.4-\mathrm{kDa}$ glycoprotein named for its role in promoting mature erythrocyte production. Studies have identified neurogenic and fibrosis features of those cells (Frede et al., 2011). In normal human bodies, EPO is maintained at a low level to produce new 
mature erythrocytes to replace aging erythrocytes. During severe bleeding, anemia, and hypoxia and under other pathological conditions, a decrease in the blood oxygen concentration, which can be sensed by kidney peritubular interstitial cells, occurs and causes an increase in EPO production mediated by hypoxia-inducible factor2 (HIF-2) (Haase, 2013). Also, the kidneys can respond to hypoxia by increasing the number of EPO-producing cells (Koury et al., 1989). EPO can enter the bone marrow and act on colony-forming units (CFU-Es) in erythroid progenitor cells to promote their differentiation into mature erythrocytes by binding with EPOR. Also, it can act on burst forming units (BFU-Es) to promote their proliferation. Studies have shown that one of the primary mechanisms by which EPO promotes the generation of mature erythrocytes is through inhibition of the apoptosis of its precursor cells during proliferation and differentiation (De Maria et al., 1999; Suzuki et al., 2003).

EPOR is a member of the type I cytokine receptor superfamily. When bound to EPO, it exists as a dimer, forming a "pocket" with the ligand-binding site at the center. The intracellular region of the receptor can recruit, bind and activate Janus Kinase 2 (JAK-2), which is a member of the nonreceptor tyrosine kinase superfamily, further leading to the phosphorylation of eight tyrosine residues in the cytoplasmic region of EPOR. These phosphorylated tyrosine residues recruit a variety of Src homology-2 (SH2) domaincontaining proteins that initiate various signaling pathways, such as PI3K/AKT, MAPK/MEK/ERK 1/2, STAT1, STAT3, and STAT5 pathways (Rossert and Eckardt, 2005).

PI3K, an intracellular phosphatidylinositol kinase, is one of the signaling molecules involved in intracellular signal transduction. Upon binding to its receptor, PI3K is activated and phosphorylates its downstream molecule AKT, which further phosphorylates GATA binding protein-1 (GATA-1). GATA-1 is a key transcription factor of hematopoietic-specific genes. It can identify almost all erythrocyte-related genes, such as bead protein and hemoglobin synthase. In erythroid progenitor cells, GATA-1 can also promote the expression of the anti-apoptotic protein bcl-xl, thereby reducing apoptosis of hematopoietic progenitor cells and maintaining their viability. Phosphorylation of GATA-1 by AKT enhances its role in promoting hematopoiesis (Chateauvieux et al., 2011; Zhao et al., 2006b). AKT also phosphorylates and inhibits the activity of the transcription factor Foxo3A, thereby downregulating the expression of Foxo3A target genes, such as cyclin-dependent kinase inhibitors and the bcl-2 family member BIM (Bakker et al., 2004). The MAPK/MEK/ERK1/2 pathway can repress the expression of caspase- 3 and thus reduce cell apoptosis (Kolbus et al., 2002). The JAK2/STAT5 pathway, a classical pathway activated by phosphorylation of JAK-2, can induce the expression of bcl-xl and thus reduce apoptosis of erythroid precursor cells (Socolovsky et al., 2001). Briefly, the pathways targeted by EPO include many cell survival and apoptosis pathways, such as those involving bcl$\mathrm{xl}, \mathrm{bcl}-2$, and caspase- 3 , which are commonly expressed in many other systems in addition to the hematopoietic system.

While the EPOR homodimer mediates erythropoiesis, the tissue-protective effects of EPO have also been proposed to be mediated partly by a common $\beta$ receptor $(\beta \mathrm{CR})$, which is shared by a granulocyte-macrophage colony-stimulating factor (GM-CSF), interleukin-3 (IL-3) and interleukin-5 (IL-5). It can bind with EPOR to form the heterodimer EPOR/ $\beta$ CR (Brines and Cerami,
2006). Knockout of the $\beta$ CR gene thoroughly represses the tissueprotective capacity of EPO in cardiomyocytes and spinal cord injury models (Brines et al., 2004), demonstrating that $\beta$ CR is essential for the tissue-protective effects of EPO.

\section{EPO in embryonic neurodevelopment}

Marti et al. (1997) showed that, in addition to being produced by the kidneys and liver, EPO is also expressed in the mouse, primate, and human brains. Both neurons and glia produce EPO in the central nervous system (Bernaudin et al., 2000). EPO and EPOR begin to be expressed in the embryonic brain, with the highest expression in the second trimester and a significant decrease in expression after birth (Knabe et al., 2004; Liu et al., 1997, 1996, 1994). Tsai et al. (2006) have shown that EPO and EPOR play an important role in embryonic neural development and that EPOR is involved in adult neurogenesis after injury. EpoR knockout mice have a normal hematopoietic system due to an endogenous hematopoietic systemspecific EPO enhancer. Still, apoptosis of neural precursor cells in the embryonic brain is increased, and neurogenesis in the subventricular zone (SVZ) in adult mice is decreased. Also, compared with those extracted from normal mice, neurons extracted from fetal EPOR knockout mice are more susceptible to hypoxia and glutamate neurotoxicity (Chen et al., 2007). Several experiments have shown that EPO can promote proliferation (Chen et al., 2007; Yu et al., 2002) and neuronal differentiation (Shingo et al., 2001) of neural precursor cells in vitro.

Epigenetic studies have shown that EPO treatment can induce a series of changes in the epigenome and the transcription of neural precursor cells, thus regulating the neural development process (Sollinger et al., 2017). By analyzing the distribution of EPOR in specific brainstem nuclei of $\mathrm{P} 25$ rats, researchers have found that EPO-EPOR signaling may play an important role in the neural control of ventilation during neural development (Schneider Gasser et al., 2019). Also, EPO treatment enhances neurogenesis and oligodendrogliomas in the SVZ, thus promoting recovery after neonatal stroke (Gonzalez et al., 2013; Iwai et al., 2010; Osredkar et al., 2010). In phase II double-blind, placebo-controlled trial, EPO combined with hypothermia for perinatal hypoxic-ischemic encephalopathy (HIE) improved early developmental outcomes (Wu et al., 2016). In summary, abundant studies have proven that EPO plays an essential regulatory role in embryonic neurogenesis and can exert a protective effect on embryonic neurogenesis in the context of ischemic damage.

\section{Adult neurogenesis during physiological conditions and after ischemic stroke}

Until the 1960s, it was believed that the adult brain is a stable structure and that neurons can only be generated during development. This view was challenged by studies indicating the existence of newly born neurons in the adult brain (Altman and Das, 1965). The SVZ of the adult brain, which contains radial glial cells (type B cells), transient amplifying intermediate progenitors (type $\mathrm{C}$ cells) and migrating neuroblasts (type A cells), can generate new neurons, which further results in neuronal replacement in the olfactory bulb (OB) (Alvarez-Buylla et al., 2000; Calzolari et al., 2015; Furutachi et al., 2015). Thousands of young neurons (type A cells) migrate into the OB in adult mice every day (Lois and AlvarezBuylla, 1994). Still, only a fraction of these cells survive to differ- 
entiate and incorporate into the local circuit.

In addition to new neurons, oligodendrocyte progenitor cells (OPCs) that differentiate into oligodendrocytes, which are responsible for myelin formation, can also be generated from type B cells and a small subpopulation of actively dividing type $\mathrm{C}$ cells. This OPCs originate from SVZ neural progenitor cells and can migrate into the corpus callosum, the striatum, and the cortex, contributing to the maintenance of axonal integrity, neural plasticity, and circuitry function (McTigue and Tripathi, 2008; Menn et al., 2006). As axon elongation is required for proper integration of newly formed neurons into the adult central nervous system (Davies et al., 1997), synaptic development in addition to cell proliferation, differentiation, and migration and incorporation of neural stem and progenitor cells must be included in the process of neurogenesis.

Another canonical region where adult neurogenesis takes place in the normal brain is the subgranular zone (SGZ) of the hippocampal dentate gyrus. Type 1 cells, the neural stem cells in the SGZ, can generate type 2 cells (intermediate progenitor cells) that initially are similar to glial cells (type 2 a cells) but are later converted to more neuronal-like cells (type $2 \mathrm{~b}$ cells), which express DCX. Type $2 \mathrm{~b}$ cells further differentiate into neuroblasts (type 3 cells). After undergoing morphological, electrophysiological, and gene expression changes (Danzer et al., 2008), type 3 cells extend their dendrites toward the molecular layer and project axons through the hilus toward the CA3 region (Zhao et al., 2006a). Neurogenesis in the SGZ contributes to the regulation of emotion and other limbic functions (Bettio et al., 2016; Zhao et al., 2006a). According to recent research, throughout the life of a mouse, cell proliferation within the SGZ continues to decline, which impairs learning and memory (Smith and Semenov, 2019; Takei, 2019).

The adult brain has been found to contain several noncanonical neurogenesis regions in addition to the SVZ and SGZ, such as the neocortex, striatum, piriform cortex, and hypothalamus (Dayer et al., 2005; Luzzati et al., 2014; Rotheneichner et al., 2018). Also, Hassouna et al. (2016) presented a novel hypothesis that neurons can be generated from inconspicuous local precursors without entering S-phase in some 'nonclassical' neurogenesis areas. However, neurogenesis in some of the above areas may occur at a very low rate (Nato et al., 2015); this needs further verification and evaluation.

Human studies of adult neurogenesis have reached different conclusions about whether human adult neurogenesis can be observed; for example, Sorrells et al. (2018) indicated that human adult neurogenesis is extremely rare and can rarely be observed in the dentate gyrus (DG), while Boldrini et al. (2018) suggested that healthy older individuals show a similar capability for producing newly born neurons in the DG as younger individuals. Thus, in the future, more research is required to better understand whether adult neurogenesis is conserved across species.

After the occurrence of transient or permanent ischemic stroke, a variety of changes occur within the neurogenic niche. According to animal studies, neurogenesis is increased in the SVZ beginning 2 days following focal ischemia, peaks at 1 week, and returns to the sham level after 2 weeks (Zhang et al., 2008). Several growth factors, such as epidermal growth factor (EGF), fibroblast growth factor (FGF), and insulin-like growth factor 1 (IGF-1), are released by the vasculature and surrounding niche cells (Wiltrout et al., 2007). After an ischemic injury, the neonatal SVZ shows increased EGF receptor (EGFR) expression on both neural stem cells and progenitors. As EGFR mediates the signaling of EGF, an increase in these proteins indicates enhanced entry of quiescent cells into the cell cycle (Alagappan et al., 2009). According to another study, after ischemic stroke, the percentage of dividing neural progenitor cells in the nonischemic V/SVZ transiently increases from 15 to $21 \%$ to $31 \%$ (Zhang et al., 2006).

In contrast, the cell cycle of those proliferating cells decreases from $19 \mathrm{~h}$ to $15.3 \mathrm{~h}$ (Zhang et al., 2006). These newly generated neuroblasts migrate in chains toward the ischemic striatum and differentiate into mature striatal neurons. These newborn neurons can functionally integrate into the adult brain after ischemic stroke and contribute to the amelioration of neurological deficits (Nakatomi et al., 2002); however, the functional significance of neurogenesis after stroke remains unclear, as less than $0.2 \%$ of damaged neurons in the infarcted striatum are replaced, and almost no mature neurons are originating from these migrated cells in the cortex at later time points (Arvidsson et al., 2002; Parent et al., 2002). In summary, relevant studies have proven that ischemic stroke can stimulate adult neurogenesis. However, the increased number of newborn neural cells is far from sufficient to restore impaired neurological function.

\section{EPO in adult neurogenesis after ischemic stroke}

$\mathrm{EPO}$, as one aspect of the intrinsic response to hypoxia-induced by hypoxia inducing factor (HIF), is increased in the cerebrum for 4 $\mathrm{h}$ after exposure to hypoxia (Chikuma et al., 2000). EPO can exert various cytoprotective effects after I/R, including reducing intracellular calcium accumulation and excitatory amino acid toxicity, inhibiting oxidative stress after stroke, decreasing apoptosis, and relieving blood-brain barrier damage after ischemic stroke. The expression of EPOR has been demonstrated to be induced after brain injury (Ott et al., 2015). Transgenic mice with constitutively active EPOR isoforms in pyramidal neurons of the cortex and hippocampus show superior cognitive performance, suggesting that active EPOR can strengthen neuronal plasticity (Sargin et al., 2011). Furthermore, EPO has also been proven to promote neurogenesis after ischemic brain injury. We will review the current research results regarding the effect of EPO on neurogenesis.

\subsection{Neural stem and progenitor cell apoptosis}

As mentioned above, adult neural stem cells persist in producing neuroblasts, which can only replace a small portion of neurons because of their high rate of apoptosis. It is known that one of the mechanisms by which EPO promotes the generation of mature erythrocytes is through the stimulation of cell survival by activating the PI3K signaling pathway (Richmond et al., 2005) or via the Bcl-2 family (Motoyama et al., 1995; Wagner et al., 2000). Using the ReNcell VM neural progenitor cell (NPC) line, researchers have identified stable expression of EPOR and HIF- $1 \alpha$ in NPCs and found that EPO/EPOR signaling can decrease the apoptosis of hNPCs (Giese et al., 2010). The embryonic brain of EpoR-null mice exhibited increased neural cell apoptosis (Chen et al., 2007). After EPO administration, the anti-apoptotic factors mcl-1 and bcl2 are significantly increased by twofold in neural progenitor cells (Wang et al., 2010), suggesting that in addition to protecting injured neurons, EPO can also decrease neural stem and progenitor 
cell apoptosis and increase the number of newborn neurons after ischemic brain injury.

\subsection{Neural progenitor cell migration}

NPC migration may be affected by the release of autocrine EPO (Merino et al., 2015). In a hypoxia/ischemic (H/I) rat model, EPO treatment enhances the migration of neuronal progenitors into the ischemic cortex and striatum (Iwai et al., 2007). Using a co-culture system of mouse brain endothelial cells (BECs) and neural progenitor cells derived from the SVZ of the adult mouse, it was found that rhEPO treatment can enhance neural progenitor cell migration by promoting the secretion of MMP2 and MMP9 by endothelial cells via the PI3K/Akt and ERK1/2 signaling pathways (Wang et al., 2006), which indicates that in addition to directly acting on neural progenitor cells, EPO can also exert indirect effects via neighboring cells; this is also discussed below.

\subsection{Neural progenitor cell proliferation}

With neural progenitor cell proliferation, different studies have reported different results. One study showed that the administration of EPO increases the proliferation of human neural progenitor cells within 4 days after application by affecting the $\mathrm{G} 2$ phase of the cell cycle (Pavlica et al., 2012). Mice were given EPO (5 U/g) for 7 days, and BrdU analysis showed that the number of actively proliferating cells in the SGZ was significantly elevated compared to that in the control group, indicating that EPO treatment enhanced the proliferation of neural progenitor cells in the SGZ (Oh et al., 2012). Compared to vehicle infusion, exogenous EPO treatment significantly increases the number of $\mathrm{Brdu}^{+}$cells in the ipsilateral $\mathrm{SVZ}$ of an H/I rat model, demonstrating that EPO can stimulate the proliferation of neuronal progenitors in the H/I brain (Iwai et al., 2007). Furthermore, in a neonatal rat stroke model, there is also a significant increase in $\mathrm{Ki}^{+} 7^{+}$proliferating cells in the striatum in EPO-treated middle cerebral artery occlusion animals compared with vehicle-treated middle cerebral artery occlusion animals (Gonzalez et al., 2013). The effect of EPO on cell cycle progression was also examined in another kind of neural progenitor cell derived from the spinal cord; it was found that EPO significantly enhances the proliferation of these cells. Cell cycle analysis of EPO-treated neural progenitor cells indicated a reduced percentage of cells in the G0/G1 phase but an increase in the cell proliferation index (S phase plus G2/M phase) (Wang et al., 2010). However, in another study, after 7 days of EPO administration, no increase in the proliferation of neural stem cells was observed (Zhang et al., 2018). A study by Hassouna et al. (2016) proved that EPO reduces the proliferating neurosphere diameter and the number of neural stem cells. These seemingly contradictory results might be caused by diverse experimental conditions, such as different sources of neural stem and progenitor cells and different detection times; this requires further verification.

\subsection{Differentiation towards neurons}

Shingo et al. (2001) found that the hypoxia-induced increase in neurogenesis by neural stem cells is mediated by autocrineparacrine EPO and exogenous that rhEPO infusion into the lateral ventricle can promote the transformation of multiple neural stem cells into neuronal progenitor cells, suggesting that EPO enhances neuronal differentiation. In an experiment using postmortem neural precursors (PM-NPCs), researchers found that the superior abil- ity of isolated PM-NPCs to achieve a neural phenotype is mediated by the activation of HIF-1 and EPO signaling (Marfia et al., 2011). In another study, the systemic administration of EPO for 3 weeks was found to increase the number of CA1/CA3 neurons by enhancing adult neurogenesis without entering the cell cycle (Hassouna et al., 2016). Furthermore, EPO facilitates neurodifferentiation while reducing cell proliferation and neurosphere formation induced by mouse induced pluripotent stem (iPS) cell-induced panneural progenitor cells (Offen et al., 2013). Therefore, EPO treatment can increase the generation of newborn neuronal cells partly by elevating differentiation into neurons.

\subsection{Oligodendrogenesis and remyelination}

In addition to its role in neurogenesis, the effect of EPO on oligodendrocyte regeneration, both during development and after injury, has been proven by many studies (Hassouna et al., 2016; O'Gorman et al., 2015; Sugawa et al., 2002). Early recombinant human EPO administration can improve white matter development in preterm infants (O'Gorman et al., 2015). EpoR expression can be detected in O4-positive immature oligodendrocytes, and different doses of EPO can promote the maturation of immature late-stage oligodendrocytes (Sugawa et al., 2002). Regarding stroke, Hassouna et al. (2016) proved that EPO treatment could significantly increase the differentiation of neural stem cells into both neurons and oligodendrocytes, suggesting that EPO has a role in the relatively rapid repair that occurs after ischemic injury by promoting remyelination as well as through other mechanisms. Another study in which $\mathrm{I} / \mathrm{R}$ and control rats were administered either vehicle or EPO also revealed an increase in both neurogenesis and oligodendrogenesis at both early and late time points (Gonzalez et al., 2013). In a focal ischemic stroke rat model, the intraperitoneal administration of rhEPO for 4 days after I/R was shown to increase the proliferation of oligodendroglial cells (Kim and Jung, 2010). In a similar model of focal ischemic stroke, 7 days of EPO treatment was shown to augment actively proliferating OPCs; 28 and 42 days after stroke, rhEPO was found to significantly increase myelinating oligodendrocytes and myelinated axons within the peri-infarct white matter (Zhang et al., 2010). In vitro, rhEPO was shown to increase the differentiation of adult SVZ neural progenitor cells into oligodendrocytes (Zhang et al., 2010). EPO/EPOR and downstream signaling pathways can induce the expression of myelin-related genes in oligodendrocytes (Cervellini et al., 2013). Kato et al. (2011) have proven that astrocytes can prevent hypoxic/reoxygenation damage to OPCs via EPO/EPOR signaling. Jantzie et al. (2013) have also found that recombinant EPO (rEPO) treatment can enhance the survival, maturation, and myelination of oligodendroglial lineage cells after prenatal transient systemic hypoxia-ischemia injury and thus promote neurological functional recovery. Delayed administration (48 $\mathrm{h}$ after H/I) of EPO promotes oligodendrogenesis and attenuates white matter injury (Iwai et al., 2010). Finally, Gyetvai et al. (2017) have suggested that EPO might increase the remyelination of oligodendrocytes by inducing insulin-like growth factors and increasing lipid metabolism. In summary, EPO can enhance oligodendrogenesis and remyelination after ischemic brain injury, thus promoting neurological function recovery.

\subsection{Astrocyte and microglial regeneration}

In addition to oligodendrocytes, astrocytes and microglia are the two other main types of glial cells in the central nervous sys- 
tem. Microglia are the primary residential inflammatory cells in the brain parenchyma, and astrocytes can also respond to tissue damage by undergoing rapid hypertrophy and hyperplasia. A previous study by our group proved that EPO could reduce the generation of new microglia and astrocytes in the brain parenchyma 14 days following cerebral ischemia (Wang et al., 2017; Zhang et al., 2019). Also, Gonzalez et al. (2007) have identified its inhibitory role in decreasing newly generated astrocytes following brain injury (Gonzalez et al., 2007). EPO can reduce the lesion-induced increase in the number of microglia (Sargin et al., 2009) and strongly attenuate injury-induced microglial motility in the brain (Mitkovski et al., 2015). However, both cell types can play contradictory roles in their interactions with neurons, as they may have either detrimental or beneficial effects depending on their mechanism of action and on the circumstances under which they are triggered. Thus, the effect of glial inhibition of erythropoietin on nerve repair still needs further confirmation.

\subsection{Angiogenesis and vascular protection}

The cerebral vasculature system has been proven to be important for neurogenesis after ischemic stroke. The endothelial cell layer of the cerebral vasculature constitutes the main component of the blood-brain barrier (BBB). Vascular endothelial cells can enhance the proliferation of neural progenitor cells by releasing extracellular signals, such as vascular endothelial growth factor (VEGF) and FGF-2 (Ruan et al., 2015).

Furthermore, microvessels supply oxygen and nutrients for neural stem cell migration, and BDNF derived from endothelial cells promotes vascular-guided neural stem cell migration (Grade et al., 2013). Newly formed blood vessels also have a role in the guidance of sprouting axons by VEGF and laminin/ $\beta 1$-integrin signaling (Jin et al., 2006; Lei et al., 2012). According to Kimakova et al. (2017), EPOR is expressed in vascular endothelial cells (ECs), and EPO can exert a substantial effect on angiogenesis after ischemic stroke (Kimakova et al., 2017). Treatment of MCAO mice with EPO enhances EPOR expression in vascular endothelial cells. It increases angiogenesis by upregulating the expression of long-term angiogenesis-related factors, thus restoring local cerebral blood flow (Li et al., 2007). Yan et al. (2016) have proven that EPO treatment can also increase VEGF expression and activate the VEGF/VEGFR-2 signaling pathway in an anoxic rat model. The effect of EPO on angiogenesis has also been demonstrated in other tissues and tumors (Annese et al., 2019; Hamed et al., 2010). Also, EPO treatment has been found to suppress apoptosis of vascular endothelial cells after ischemic injury through the direct modulation of Akt1 phosphorylation, mitochondrial membrane potential, and cysteine protease activity (Chong et al., 2002). EPO can also relieve BBB injury by suppressing the expression of matrix metalloproteinases (MMPs) (Wang et al., 2015) and upregulating aquaporin-4 (AQP4) (Chu et al., 2014). In summary, all of the above results suggest that EPO can indirectly promote neurogenesis after ischemic injury by promoting angiogenesis or enhancing endothelial cell survival.

\section{Prospects of clinical transformation}

Based on the above discussion, we can conclude that EPO can promote neurological function recovery by enhancing neurogenesis after ischemic stroke. However, issues concerning the safety and effectiveness of the administration of EPO as a neurotrophic and neuroprotective factor remain. Many clinical trials have been conducted, and some of them have obtained positive results, confirming the clinical translation potential of EPO (Ehrenreich et al., 2002; Tsai et al., 2015). EPO has also shown potential in alleviating cerebral palsy (CP) (Lee et al., 2014; Min et al., 2013), which is a common sequela of ischemic stroke. However, Ehrenreich et al. (2009) found that EPO combined with thrombolytic therapy may increase the risk of severe side effects such as cerebral hemorrhage, thrombosis, and edema. Of note, it was proposed that the inclusion of patients receiving tPA caused the poorer outcomes observed in this study compared to those observed in previous positive trials.

Further animal experiments revealed that tPA-EPO interactions are related to excessive matrix metalloproteinase activation, promotion of vascular permeability, and upregulation of NF-kappaB and interleukin-1 receptor-associated kinase-1 (Jia et al., 2010; Zechariah et al., 2010) thus increase edema. Previous studies have shown that in addition to causing cerebral hemorrhage, thrombosis, and edema, EPO has various other adverse effects; for example, some studies have suggested that EPO has the tumor-promoting ability (Liu et al., 2020). Hypertension is a significant adverse effect of EPO treatment that is associated with NO, endothelins, and the sympathoadrenal and renin-angiotensin pathways (Agarwal, 2018). Therefore, further research is needed to increase the safety and effectiveness of EPO administration in clinical applications.

\subsection{Combination of EPO with other agents}

Multiple interconnected pathways mediate cerebral injury after ischemic stroke. When one pathway is suppressed, other pathways continue to mediate cell damage. Therefore, a single drug targeting one or several pathways is unlikely to be effective after ischemic injury. The combination of complementary treatments is a more meaningful strategy for future therapy. According to the results of a recent study, the composite-mediated, sequential delivery of pegylated EGF and EPO minimizes damage in a mouse stroke model (Wang et al., 2013). The results of another experimental study by Liu et al. (2010) showed a significantly greater number of proliferating neural progenitor cells and newborn mature neural cells in EPO + G-CSF-treated rats than in EPO-, G-CSF-, or saline-treated rats. In a rat stroke model, researchers compared the effects of the sequential administration of EPO and human chorionic gonadotropin (hCG) with the effects of either of these two compounds alone (Belayev et al., 2009). The results proved that the two growth factors together are more effective than one drug in restoring neurological function (Belayev et al., 2009). In summary, considering EPO as a supplementary therapy and investigating its effect and safety when combined with other potential agents may increase the potential for its future clinical translation. Considering the above-mentioned severe side effects caused by the combination of tPA-EPO, potential interactions between different agents must be considered.

\subsection{Development of EPO derivatives}

As a consequence of the low rate at which EPO crosses the brain-blood barrier (Banks et al., 2004), it must be administered at large doses to achieve an effective blood concentration. Although a single administration of a high dose of does not lead to increased viscosity, repeated administration of large doses of EPO can stim- 
ulate the production of mature erythrocytes and platelets, which increases blood viscosity and leads to thrombosis and other severe complications (McDonald et al., 1992). To avoid these side effects of EPO, researchers have developed several derivates of EPO and explored their effects in ischemic stroke as follows.

Carbamylated EPO (CEPO) is a derivative of EPO that cannot promote the generation of mature erythrocytes. Leist et al. (2004) have shown that CEPO retains the tissue-protective function of EPO. CEPO has been proven to promote the neural differentiation of neural stem cells and neurite outgrowth. The activation of Stat3, Stat5, and Akt might be involved in these processes (Fu et al., 2010). Oh et al. (2012) also proved that the length of neurites and spine density of MAP-2-positive cells in the SGZ is significantly increased by CEPO treatment. CEPO-induced gene expression and signaling cascades in the rat dentate gyrus have been indicated to be involved in neurogenesis and memory formation (Tiwari et al., 2019). In an in vivo study by Choi et al. (2014), the treatment of cells with CEPO was shown to markedly enhance neuronal differentiation and spine formation via the acetylation of transcription factors and subsequent transactivation of target genes. Treatment of healthy adult mice with CEPO and EPO for seven days can promote hippocampal neurogenesis and neuronal differentiation (Leconte et al., 2011; Oh et al., 2012).

Furthermore, the ability of CEPO to promote neurogenesis was also proven in a traumatic brain injury (TBI) model in rats (Xiong et al., 2011). A newly developed carbamylated EPOFC fusion protein (cEPO-FC) was also proven to restore motor evoked potentials (MEPs) in both pig and rabbit models of ischemic spinal cord dysfunction and neuronal damage (Simon et al., 2011, 2016). The Shh/Mash1 signaling pathway has been proven to mediate CEPO-enhanced neurogenesis by regulating neuronal differentiation (Wang et al., 2007). Another EPO derivative, asialoerythropoietin (AEPO), which is generated by the total enzymatic desialylation of rhEPO, has been demonstrated to promote the maturation of V-SVZ-originated OPCs in the injured white matter of neonatal mice without affecting hematopoiesis (Kaneko et al., 2013). Treatment with asialo-erythropoietin in another perinatal HI mouse model was proven to promote the differentiation of SVZoriginated OPCs and thus enhance neurological function recovery without causing erythropoiesis (Kako et al., 2012). Until now, there have been no complicated human clinical trials on the neuroprotective effect of EPO derivatives.

\section{Conclusions}

In conclusion, as adult neurogenesis is a complex physiological process, current studies are not sufficient to reach a consensus on which step EPO acts. Therefore, mechanistic studies are needed. As mentioned above, the effectiveness of EPO is insufficient for clinical transformation. In terms of safety, EPOR has been identified to be expressed in many cancer cells in addition to thrombosis and cerebral hemorrhage and has been proven to be related to the occurrence and development of tumors (Cevik et al., 2018; Chan et al., 2017a; Zsokova et al., 2019). Thus, more studies are needed on how to avoid the side effects of EPO and improve its positive effects. Furthermore, human neurogenesis, which has also been demonstrated in studies involving comprehensive assessments of ${ }^{14} \mathrm{C}$ content, has been proven to substantially differ from neurogenesis in rodents (Spalding et al., 2013). Clarifying these differences is necessary for future clinical translation.

Despite the emerging problems and controversies after 30 years of research on the effect of EPO in ischemic stroke, basic research on its neuroprotective and neurogenic effects is still important because of its multiple protective effects on stroke, especially the long-term effect of its application after the acute phase. With more research proving the therapeutic effect of EPO derivatives, mutant EPO may be a future direction of the clinical translation of EPO.

\section{Abbreviations}

AEPO: Asialo-EPO; AQP4: Aquaporin-4; BBB: Blood-brain barrier; BDNF: Brain-derived neurotrophic factor; BECs: Brain endothelial cells; BFU-Es: Burst forming units; CEPO: Carbamylated EPO; cEPO-FC: Carbamylated EPO-FC fusion protein; CFU-Es: Colony forming units; CP: Cerebral palsy; DG: Dentate gyrus; ECs: Endothelial cells; EGF: Epidermal growth factor; EPO: Erythropoietin; EPOR: EPO receptor; GABA: Gammaaminobutyric acid; GATA-1: GATA binding protein-1; G-CSF: Granulocyte-colony stimulating factor; GM-CSF: Granulocytemacrophage colony-stimulating factor; hCG: Human chorionic gonadotropin; H/I: Hypoxia/ischemic; HIE: Hypoxic-ischemic encephalopathy; HIF-2: Hypoxia-inducible factor-2; IGF-1: Insulinlike growth factor 1; IL-3: Interleukin-3; IL-5: Interleukin-5; iPS: Induced pluripotent stem; I/R: Ischemia/reperfusion; MAPK: Mitogen-activated protein kinase; MEP: Motor evoked potentials; MMPs: Matrix metalloproteinases; NGF: Nerve growth factor; NMDA: N-Methyl-D-aspartic acid; NPC: Neural progenitor cell; OB: Olfactory bulb; OPCs: Oligodendrocyte progenitor cells; PI3K: Phosphoinositide 3-kinase; PKB: Protein kinase B; PMNPCs: Postmortem neural precursors; rEPO: Recombinant EPO; rtPA: Recombinant tissue plasminogen activator; SGZ: Subgranular zone; SH2: Src homology-2; STAT: Signal transducers and activators of transcription; SVZ: Subventricular zone; TBI: Traumatic brain injury; VEGF: Vascular endothelial growth factor; $\beta \mathrm{CR}$ : Common $\beta$ receptor.

\section{Acknowledgments}

This project was supported by the National Natural Science Foundation of China (81801149, 81641054, and 81471340).

\section{Conflict of Interest}

The authors declare no conflicts of interest.

Submitted: January 07, 2020

Revised: June 18, 2020

Accepted: June 28, 2020

Published: September 30, 2020

\section{References}

Agarwal, R. (2018) Mechanisms and mediators of hypertension induced by erythropoietin and related molecules. Nephrology Dialysis Transplantation 33, 1690-1698.

Alagappan, D., Lazzarino, D. A., Felling, R. J., Balan, M., Kotenko, S. V. and Levison, S. W. (2009) Brain injury expands the numbers of neural stem cells and progenitors in the SVZ by enhancing their responsiveness to EGF. ASN Neuro 1, e00009.

Alnaeeli, M., Wang, L., Piknova, B., Rogers, H., Li, X. and Noguchi, C. T. (2012) Erythropoietin in brain development and beyond. Anatomy Research International 2012, 953264.

Altman, J. and Das, G. D. (1965) Autoradiographic and histological ev- 
idence of postnatal hippocampal neurogenesis in rats. The Journal of Comparative Neurology 124, 319-335.

Alvarez-Buylla, A., Herrera, D. G. and Wichterle, H. (2000) The subventricular zone: source of neuronal precursors for brain repair. Progress in Brain Research 127, 1-11.

Anagnostou, A., Liu, Z., Steiner, M., Chin, K., Lee, E. S., Kessimian, N. and Noguchi, C. T. (1994) Erythropoietin receptor mRNA expression in human endothelial cells. Proceedings of the National Academy of Sciences of the United States of America 91, 3974-3978.

Annese, T., Tamma, R., Ruggieri, S. and Ribatti, D. (2019) Erythropoietin in tumor angiogenesis. Experimental Cell Research 374, 266-273.

Arvidsson, A., Collin, T., Kirik, D., Kokaia, Z. and Lindvall, O. (2002) Neuronal replacement from endogenous precursors in the adult brain after stroke. Nature Medicine 8, 963-970.

Bakker, W. J., Blazquez-Domingo, M., Kolbus, A., Besooyen, J., Steinlein, P., Beug, H., Coffer, P. J., Lowenberg, B., von Lindern, M. and van Dijk, T. B. (2004) FoxO3a regulates erythroid differentiation and induces BTG1, an activator of protein arginine methyl transferase 1 . Journal of Cell Biology 164, 175-184.

Banks, W. A., Jumbe, N. L., Farrell, C. L., Niehoff, M. L. and Heatherington, A. C. (2004) Passage of erythropoietic agents across the bloodbrain barrier: a comparison of human and murine erythropoietin and the analog darbepoetin alfa. European Journal of Pharmacology 505, 93-101.

Belayev, L., Khoutorova, L., Zhao, K. L., Davidoff, A. W., Moore, A. F. and Cramer, S. C. (2009) A novel neurotrophic therapeutic strategy for experimental stroke. Brain Research 1280, 117-123.

Bernaudin, M., Bellail, A., Marti, H. H., Yvon, A., Vivien, D., Duchatelle, I., Mackenzie, E. T. and Petit, E. (2000) Neurons and astrocytes express EPO mRNA: oxygen-sensing mechanisms that involve the redox-state of the brain. Glia 30, 271-278.

Bettio, L. E., Neis, V. B., Pazini, F. L., Brocardo, P. S., Patten, A. R., Gil-Mohapel, J., Christie, B. R. and Rodrigues, A. L. (2016) The antidepressant-like effect of chronic guanosine treatment is associated with increased hippocampal neuronal differentiation. European Journal of Neuroscience 43, 1006-1015.

Boldrini, M., Fulmore, C. A., Tartt, A. N., Simeon, L. R., Pavlova, I., Poposka, V., Rosoklija, G. B., Stankov, A., Arango, V., Dwork, A. J., Hen, R. and Mann, J. J. (2018) Human hippocampal neurogenesis persists throughout aging. Cell Stem Cell 22, 589-599.

Brines, M. and Cerami, A. (2006) Discovering erythropoietin's extrahematopoietic functions: biology and clinical promise. Kidney International 70, 246-250.

Brines, M., Grasso, G., Fiordaliso, F., Sfacteria, A., Ghezzi, P., Fratelli, M., Latini, R., Xie, Q. W., Smart, J., Su-Rick, C. J., Pobre, E., Diaz, D., Gomez, D., Hand, C., Coleman, T. and Cerami, A. (2004) Erythropoietin mediates tissue protection through an erythropoietin and common beta-subunit heteroreceptor. Proceedings of the National Academy of Sciences of the United States of America 101, 14907-14912.

Calzolari, F., Michel, J., Baumgart, E. V., Theis, F., Gotz, M. and Ninkovic, J. (2015) Fast clonal expansion and limited neural stem cell self-renewal in the adult subependymal zone. Nature Neuroscience 18, 490-492.

Cervellini, I., Annenkov, A., Brenton, T., Chernajovsky, Y., Ghezzi, P. and Mengozzi, M. (2013) Erythropoietin (EPO) increases myelin gene expression in CG4 oligodendrocyte cells through the classical EPO receptor. Molecular Medicine 19, 223-229.

Cevik, S., Kitis, S., Evran, S., Akkaya, E., Tosuner, Z. and Hanimoglu, H. (2018) The relationship of erythropoietin receptor expression and prognosis in glioblastoma multiforme patients. Nigerian Journal of Clinical Practice 21, 502-506.

Chan, K. K., Matchett, K. B., Coulter, J. A., Yuen, H. F., McCrudden, C. M., Zhang, S. D., Irwin, G. W., Davidson, M. A., Rulicke, T., Schober, S., Hengst, L., Jaekel, H., Platt-Higgins, A., Rudland, P. S., Mills, K. I., Maxwell, P., El-Tanani, M. and Lappin, T. R. (2017a) Erythropoietin drives breast cancer progression by activation of its receptor EPOR. Oncotarget 8, 38251-38263.

Chan, S. J., Love, C., Spector, M., Cool, S. M., Nurcombe, V. and Lo, E. H. (2017b) Endogenous regeneration: Engineering growth factors for stroke. Neurochemistry International 107, 57-65.

Chateauvieux, S., Grigorakaki, C., Morceau, F., Dicato, M. and Diederich,
M. (2011) Erythropoietin, erythropoiesis and beyond. Biochemical Pharmacology 82, 1291-1303.

Chen, Z. Y., Asavaritikrai, P., Prchal, J. T. and Noguchi, C. T. (2007) Endogenous erythropoietin signaling is required for normal neural progenitor cell proliferation. Journal of Biological Chemistry 282, 2587525883.

Chi, O. Z., Hunter, C., Liu, X. and Weiss, H. R. (2008) Effects of erythropoietin on blood-brain barrier disruption in focal cerebral ischemia. Pharmacology 82, 38-42.

Chikuma, M., Masuda, S., Kobayashi, T., Nagao, M. and Sasaki, R. (2000) Tissue-specific regulation of erythropoietin production in the murine kidney, brain, and uterus. The American Journal of PhysiologyEndocrinology and Metabolism 279, E1242-E1248.

Choi, M., Ko, S. Y., Lee, I. Y., Wang, S. E., Lee, S. H., Oh, D. H., Kim, Y. S. and Son, H. (2014) Carbamylated erythropoietin promotes neurite outgrowth and neuronal spine formation in association with $\mathrm{CBP} / \mathrm{p} 300$. Biochemical and Biophysical Research Communications 446, 79-84.

Chong, Z. Z., Kang, J. Q. and Maiese, K. (2002) Erythropoietin is a novel vascular protectant through activation of Akt1 and mitochondrial modulation of cysteine proteases. Circulation 106, 2973-2979.

Chu, H., Ding, H., Tang, Y. and Dong, Q. (2014) Erythropoietin protects against hemorrhagic blood-brain barrier disruption through the effects of aquaporin-4. Laboratory Investigation 94, 1042-1053.

Danzer, S. C., Kotloski, R. J., Walter, C., Hughes, M. and McNamara, J. O. (2008) Altered morphology of hippocampal dentate granule cell presynaptic and postsynaptic terminals following conditional deletion of TrkB. Hippocampus 18, 668-678.

Davies, S. J., Fitch, M. T., Memberg, S. P., Hall, A. K., Raisman, G. and Silver, J. (1997) Regeneration of adult axons in white matter tracts of the central nervous system. Nature 390, 680-683.

Dayer, A. G., Cleaver, K. M., Abouantoun, T. and Cameron, H. A. (2005) New GABAergic interneurons in the adult neocortex and striatum are generated from different precursors. Journal of Cell Biology 168, 415427.

De Maria, R., Zeuner, A., Eramo, A., Domenichelli, C., Bonci, D., Grignani, F., Srinivasula, S. M., Alnemri, E. S., Testa, U. and Peschle, C. (1999) Negative regulation of erythropoiesis by caspase-mediated cleavage of GATA-1. Nature 401, 489-493.

Ehrenreich, H., Hasselblatt, M., Dembowski, C., Cepek, L., Lewczuk, P., Stiefel, M., Rustenbeck, H. H., Breiter, N., Jacob, S., Knerlich, F., Bohn, M., Poser, W., Ruther, E., Kochen, M., Gefeller, O., Gleiter, C., Wessel, T. C., De Ryck, M., Itri, L., Prange, H., Cerami, A., Brines, M. and Siren, A. L. (2002) Erythropoietin therapy for acute stroke is both safe and beneficial. Molecular Medicine 8, 495-505.

Ehrenreich, H., Weissenborn, K., Prange, H., Schneider, D., Weimar, C., Wartenberg, K., Schellinger, P. D., Bohn, M., Becker, H., Wegrzyn, M., Jahnig, P., Herrmann, M., Knauth, M., Bahr, M., Heide, W., Wagner, A., Schwab, S., Reichmann, H., Schwendemann, G., Dengler, R., Kastrup, A., Bartels, C. and Group EPOST. (2009) Recombinant human erythropoietin in the treatment of acute ischemic stroke. Stroke 40, e647-e656.

Fisher, J. W., Koury, S., Ducey, T. and Mendel, S. (1996) Erythropoietin production by interstitial cells of hypoxic monkey kidneys. British Journal of Haematology 95, 27-32.

Frede, S., Freitag, P., Geuting, L., Konietzny, R. and Fandrey, J. (2011) Oxygen-regulated expression of the erythropoietin gene in the human renal cell line REPC. Blood 117, 4905-4914.

Fu, Z. Q., Shao, Q. L., Shen, J. L., Zhang, Y. J., Zhao, X. X. and Yao, L. (2010) Effect of carbamylated erythropoietin on major histocompatibility complex expression and neural differentiation of human neural stem cells. Journal of Neuroimmunology 221, 15-24.

Furutachi, S., Miya, H., Watanabe, T., Kawai, H., Yamasaki, N., Harada, Y., Imayoshi, I., Nelson, M., Nakayama, K. I., Hirabayashi, Y. and Gotoh, Y. (2015) Slowly dividing neural progenitors are an embryonic origin of adult neural stem cells. Nature Neuroscience 18, 657-665.

Giese, A. K., Frahm, J., Hubner, R., Luo, J., Wree, A., Frech, M. J., Rolfs, A. and Ortinau, S. (2010) Erythropoietin and the effect of oxygen during proliferation and differentiation of human neural progenitor cells. $B M C$ Cell Biology 11, 94.

Gonzalez, F. F., Larpthaveesarp, A., McQuillen, P., Derugin, N., Wendland, 
M., Spadafora, R. and Ferriero, D. M. (2013) Erythropoietin increases neurogenesis and oligodendrogliosis of subventricular zone precursor cells after neonatal stroke. Stroke 44, 753-758.

Gonzalez, F. F., McQuillen, P., Mu, D., Chang, Y., Wendland, M., Vexler, Z. and Ferriero, D. M. (2007) Erythropoietin enhances long-term neuroprotection and neurogenesis in neonatal stroke. Developmental Neuroscience 29, 321-330.

Grade, S., Weng, Y. C., Snapyan, M., Kriz, J., Malva, J. O. and Saghatelyan, A. (2013) Brain-derived neurotrophic factor promotes vasculature-associated migration of neuronal precursors toward the ischemic striatum. PLoS One 8, e55039.

Gyetvai, G., Hughes, T., Wedmore, F., Roe, C., Heikal, L., Ghezzi, P. and Mengozzi, M. (2017) Erythropoietin increases myelination in oligodendrocytes: gene expression profiling reveals early induction of genes involved in lipid transport and metabolism. Frontiers in Immunology $\mathbf{8}$, 1394.

Haase, V. H. (2013) Regulation of erythropoiesis by hypoxia-inducible factors. Blood Reviews 27, 41-53.

Hamed, S., Egozi, D., Kruchevsky, D., Teot, L., Gilhar, A. and Ullmann, Y. (2010) Erythropoietin improves the survival of fat tissue after its transplantation in nude mice. PLoS One 5, e13986.

Hassouna, I., Ott, C., Wustefeld, L., Offen, N., Neher, R. A., Mitkovski, M., Winkler, D., Sperling, S., Fries, L., Goebbels, S., Vreja, I. C., Hagemeyer, N., Dittrich, M., Rossetti, M. F., Krohnert, K., Hannke, K., Boretius, S., Zeug, A., Hoschen, C., Dandekar, T., Dere, E., Neher, E., Rizzoli, S. O., Nave, K. A., Siren, A. L. and Ehrenreich, H. (2016) Revisiting adult neurogenesis and the role of erythropoietin for neuronal and oligodendroglial differentiation in the hippocampus. Molecular Psychiatry 21, 1752-1767.

Iwai, M., Cao, G., Yin, W., Stetler, R. A., Liu, J. and Chen, J. (2007) Erythropoietin promotes neuronal replacement through revascularization and neurogenesis after neonatal hypoxia/ischemia in rats. Stroke 38, 2795-2803.

Iwai, M., Stetler, R. A., Xing, J., Hu, X., Gao, Y., Zhang, W., Chen, J. and Cao, G. (2010) Enhanced oligodendrogenesis and recovery of neurological function by erythropoietin after neonatal hypoxic/ischemic brain injury. Stroke 41, 1032-1037.

Jantzie, L. L., Miller, R. H. and Robinson, S. (2013) Erythropoietin signaling promotes oligodendrocyte development following prenatal systemic hypoxic-ischemic brain injury. Pediatric Research 74, 658-667.

Jia, L., Chopp, M., Zhang, L., Lu, M. and Zhang, Z. (2010) Erythropoietin in combination of tissue plasminogen activator exacerbates brain hemorrhage when treatment is initiated 6 hours after stroke. Stroke 41, 2071-2076.

Jin, K., Mao, X. O. and Greenberg, D. A. (2006) Vascular endothelial growth factor stimulates neurite outgrowth from cerebral cortical neurons via Rho kinase signaling. Journal of Neurobiology 66, 236-242.

Kako, E., Kaneko, N., Aoyama, M., Hida, H., Takebayashi, H., Ikenaka, K., Asai, K., Togari, H., Sobue, K. and Sawamoto, K. (2012) Subventricular zone-derived oligodendrogenesis in injured neonatal white matter in mice enhanced by a nonerythropoietic erythropoietin derivative. Stem Cells 30, 2234-2247.

Kato, S., Aoyama, M., Kakita, H., Hida, H., Kato, I., Ito, T., Goto, T., Hussein, M. H., Sawamoto, K., Togari, H. and Asai, K. (2011) Endogenous erythropoietin from astrocyte protects the oligodendrocyte precursor cell against hypoxic and reoxygenation injury. Journal of Neuroscience Research 89, 1566-1574.

Kaneko, N., Kako, E. and Sawamoto, K. (2013) Enhancement of ventricular-subventricular zone-derived neurogenesis and oligodendrogenesis by erythropoietin and its derivatives. Frontiers in Cellular Neuroscience 7, 235 .

Kim, Y. J. and Jung, Y. W. (2010) Systemic injection of recombinant human erythropoietin after focal cerebral ischemia enhances oligodendroglial and endothelial progenitor cells in rat brain. Anatomy and Cell Biology 43, 140-149.

Kimakova, P., Solar, P., Solarova, Z., Komel, R. and Debeljak, N. (2017) Erythropoietin and its angiogenic activity. International Journal of Molecular Sciences 18, 1519.

Knabe, W., Knerlich, F., Washausen, S., Kietzmann, T., Siren, A. L., Brunnett, G., Kuhn, H. J. and Ehrenreich, H. (2004) Expression patterns of erythropoietin and its receptor in the developing midbrain. Anatomy and Embryology 207, 503-512

Kolbus, A., Pilat, S., Husak, Z., Deiner, E. M., Stengl, G., Beug, H. and Baccarini, M. (2002) Raf-1 antagonizes erythroid differentiation by restraining caspase activation. Journal of Experimental Medicine 196, 1347-1353.

Koury, S. T., Koury, M. J., Bondurant, M. C., Caro, J. and Graber, S. E. (1989) Quantitation of erythropoietin-producing cells in kidneys of mice by in situ hybridization: correlation with hematocrit, renal erythropoietin mRNA, and serum erythropoietin concentration. Blood 74, 645-651.

Leconte, C., Bihel, E., Lepelletier, F. X., Bouet, V., Saulnier, R., Petit, E., Boulouard, M., Bernaudin, M. and Schumann-Bard, P. (2011) Comparison of the effects of erythropoietin and its carbamylated derivative on behaviour and hippocampal neurogenesis in mice. Neuropharmacology 60, 354-364.

Lee, H. S., Song, J., Min, K., Choi, Y. S., Kim, S. M., Cho, S. R. and Kim, M. (2014) Short-term effects of erythropoietin on neurodevelopment in infants with cerebral palsy: a pilot study. Brain and Development 36, 764-769.

Lei, W. L., Xing, S. G., Deng, C. Y., Ju, X. C., Jiang, X. Y. and Luo, Z. G. (2012) Laminin/beta1 integrin signal triggers axon formation by promoting microtubule assembly and stabilization. Cell Research 22, 954-972.

Leist, M., Ghezzi, P., Grasso, G., Bianchi, R., Villa, P., Fratelli, M., Savino, C., Bianchi, M., Nielsen, J., Gerwien, J., Kallunki, P., Larsen, A. K., Helboe, L., Christensen, S., Pedersen, L. O., Nielsen, M., Torup, L., Sager, T., Sfacteria, A., Erbayraktar, S., Erbayraktar, Z., Gokmen, N., Yilmaz, O., Cerami-Hand, C., Xie,. Q. W., Coleman, T., Cerami, A. and Brines, M. (2004) Derivatives of erythropoietin that are tissue protective but not erythropoietic. Science 305, 239-242.

Li, Y., Lu, Z., Keogh, C. L., Yu, S. P. and Wei, L. (2007) Erythropoietininduced neurovascular protection, angiogenesis, and cerebral blood flow restoration after focal ischemia in mice. Journal of Cerebral Blood Flow \& Metabolism 27, 1043-1054.

Liu, C., Shen, K., Liu, Z. and Noguchi, C. T. (1997) Regulated human erythropoietin receptor expression in mouse brain. Journal of Biological Chemistry 272, 32395-32400.

Liu, C., Yu, K., Shen, K., Liu, Z. and Noguchi, C. T. (1996) Transgenic mice containing the human erythropoietin receptor gene exhibit correct hematopoietic and neural expression. Proceedings of the Association of American Physicians 108, 449-454.

Liu, S. P., Lee, S. D., Lee, H. T., Liu, D. D., Wang, H. J., Liu, R. S., Lin, S. Z., Su, C. Y., Li, H. and Shyu, W. C. (2010) Granulocyte colonystimulating factor activating HIF-1alpha acts synergistically with erythropoietin to promote tissue plasticity. PloS One 5, e10093.

Liu, W., Varier, K. M., Sample, K. M., Zacksenhaus, E., Gajendran, B. and Ben-David, Y. (2020) Erythropoietin signaling in the microenvironment of tumors and healthy tissues. Advances in Experimental Medicine and Biology 1223, 17-30.

Liu, Z. Y., Chin, K. and Noguchi, C. T. (1994) Tissue specific expression of human erythropoietin receptor in transgenic mice. Developmental Biology 166, 159-169.

Lois, C. and Alvarez-Buylla, A. (1994) Long-distance neuronal migration in the adult mammalian brain. Science 264, 1145-1148.

Luft, A. R., Macko, R. F., Forrester, L. W., Villagra, F., Ivey, F., Sorkin, J. D., Whitall, J., McCombe-Waller, S., Katzel, L., Goldberg, A. P. and Hanley, D. F. (2008) Treadmill exercise activates subcortical neural networks and improves walking after stroke: a randomized controlled trial. Stroke 39, 3341-3350.

Luzzati, F., Nato, G., Oboti, L., Vigna, E., Rolando, C., Armentano, M., Bonfanti, L., Fasolo, A. and Peretto, P. (2014) Quiescent neuronal progenitors are activated in the juvenile guinea pig lateral striatum and give rise to transient neurons. Development 141, 4065-4075.

Marfia, G., Madaschi, L., Marra, F., Menarini, M., Bottai, D., Formenti, A., Bellardita, C., Di Giulio, A. M., Carelli, S. and Gorio, A. (2011) Adult neural precursors isolated from post mortem brain yield mostly neurons: an erythropoietin-dependent process. Neurobiology of Disease 
43, 86-98.

Marti, H. H., Gassmann, M., Wenger, R. H., Kvietikova, I., MorgantiKossmann, M. C., Kossmann, T., Trentz, O. and Bauer, C. (1997) Detection of erythropoietin in human liquor: intrinsic erythropoietin production in the brain. Kidney International 51, 416-418.

McDonald, T. P., Clift, R. E. and Cottrell, M. B. (1992) Large, chronic doses of erythropoietin cause thrombocytopenia in mice. Blood 80, 352-358.

McTigue, D. M. and Tripathi, R. B. (2008) The life, death, and replacement of oligodendrocytes in the adult CNS. Journal of Neurochemistry 107, $1-19$.

Menn, B., Garcia-Verdugo, J. M., Yaschine, C., Gonzalez-Perez, O., Rowitch, D. and Alvarez-Buylla, A. (2006) Origin of oligodendrocytes in the subventricular zone of the adult brain. Journal of Neuroscience 26, 7907-7918.

Merino, J. J., Bellver-Landete, V., Oset-Gasque, M. J. and Cubelos, B. (2015) CXCR4/CXCR7 molecular involvement in neuronal and neural progenitor migration: focus in CNS repair. Journal of Cellular Physiology 230, 27-42.

Min, K., Song, J., Kang, J. Y., Ko, J., Ryu, J. S., Kang, M. S., Jang, S. J., Kim, S. H., Oh, D., Kim, M. K., Kim, S. S. and Kim, M. (2013) Umbilical cord blood therapy potentiated with erythropoietin for children with cerebral palsy: a double-blind, randomized, placebo-controlled trial. Stem Cells 31, 581-591.

Mitkovski, M., Dahm, L., Heinrich, R., Monnheimer, M., Gerhart, S., Stegmuller, J., Hanisch, U. K., Nave, K. A. and Ehrenreich, H. (2015) Erythropoietin dampens injury-induced microglial motility. Journal of Cerebral Blood Flow and Metabolism 35, 1233-1236.

Motoyama, N., Wang, F., Roth, K. A., Sawa, H., Nakayama, K., Nakayama, K., Negishi, I., Senju, S., Zhang, Q., Fujii, S. and Loh, D. Y. (1995) Massive cell death of immature hematopoietic cells and neurons in Bcl$\mathrm{X}$-deficient mice. Science 267, 1506-1510.

Nagai, A., Nakagawa, E., Choi, H. B., Hatori, K., Kobayashi, S. and Kim, S. U. (2001) Erythropoietin and erythropoietin receptors in human CNS neurons, astrocytes, microglia, and oligodendrocytes grown in culture. Journal of Neuropathology and Experimental Neurology 60, 386-392.

Nakatomi, H., Kuriu, T., Okabe, S., Yamamoto, S., Hatano, O., Kawahara, N., Tamura, A., Kirino, T. and Nakafuku, M. (2002) Regeneration of hippocampal pyramidal neurons after ischemic brain injury by recruitment of endogenous neural progenitors. Cell 110, 429-441.

Nato, G., Caramello, A., Trova, S., Avataneo, V., Rolando, C., Taylor, V., Buffo, A., Peretto, P. and Luzzati, F. (2015) Striatal astrocytes produce neuroblasts in an excitotoxic model of Huntington's disease. Development 142, 840-845.

O'Gorman, R. L., Bucher, H. U., Held, U., Koller, B. M., Huppi, P. S., Hagmann, C. F. and Swiss EPO Neuroprotection Trial Group. (2015) Tract-based spatial statistics to assess the neuroprotective effect of early erythropoietin on white matter development in preterm infants. Brain 138, 388-397.

Offen, N., Flemming, J., Kamawal, H., Ahmad, R., Wolber, W., Geis, C., Zaehres, H., Scholer, H. R., Ehrenreich, H., Muller, A. M. and Siren, A. L. (2013) Effects of erythropoietin in murine-induced pluripotent cellderived panneural progenitor cells. Molecular Medicine 19, 399-408.

Oh, D. H., Lee, I. Y., Choi, M., Kim, S. H. and Son, H. (2012) Comparison of neurite outgrowth induced by erythropoietin (EPO) and carbamylated erythropoietin (CEPO) in hippocampal neural progenitor cells. The Korean Journal of Physiology and Pharmacology 16, 281-285.

Osredkar, D., Sall, J. W., Bickler, P. E. and Ferriero, D. M. (2010) Erythropoietin promotes hippocampal neurogenesis in in vitro models of neonatal stroke. Neurobiology of Disease 38, 259-265.

Ostrowski, D. and Heinrich, R. (2018) Alternative erythropoietin receptors in the nervous system. Clinical Medicine 7, 24.

Ott, C., Martens, H., Hassouna, I., Oliveira, B., Erck, C., Zafeiriou, M. P., Peteri, U. K., Hesse, D., Gerhart, S., Altas, B., Kolbow, T., Stadler, H., Kawabe, H., Zimmermann, W. H., Nave, K. A., Schulz-Schaeffer, W., Jahn, O. and Ehrenreich, H. (2015) Widespread expression of erythropoietin receptor in brain and its induction by injury. Molecular Medicine 21, 803-815.

Parent, J. M., Vexler, Z. S., Gong, C., Derugin, N. and Ferriero, D. M. (2002) Rat forebrain neurogenesis and striatal neuron replacement after focal stroke. Annals of Neurology 52, 802-813.
Pavlica, S., Milosevic, J., Keller, M., Schulze, M., Peinemann, F., Piscioneri, A., De Bartolo, L., Darsow, K., Bartel, S., Lange, H. A. and Bader, A. (2012) Erythropoietin enhances cell proliferation and survival of human fetal neuronal progenitors in normoxia. Brain Research 1452, $18-28$.

Pin-Barre, C. and Laurin, J. (2015) Physical exercise as a diagnostic, rehabilitation, and preventive tool: influence on neuroplasticity and motor recovery after stroke. Neural Plasticity 2015, 608581.

Richmond, T. D., Chohan, M. and Barber, D. L. (2005) Turning cells red: signal transduction mediated by erythropoietin. Trends Cell Biology 15, 146-155.

Rossert, J. and Eckardt, K. U. (2005) Erythropoietin receptors: their role beyond erythropoiesis. Nephrology Dialysis Transplantation 20, 10251028.

Rotheneichner, P., Belles, M., Benedetti, B., Konig, R., Dannehl, D., Kreutzer, C., Zaunmair, P., Engelhardt, M., Aigner, L., Nacher, J. and Couillard-Despres, S. (2018) Cellular plasticity in the adult murine piriform cortex: continuous maturation of dormant precursors into excitatory neurons. Cereb Cortex 28, 2610-2621.

Ruan, L., Wang, B., ZhuGe, Q. and Jin, K. (2015) Coupling of neurogenesis and angiogenesis after ischemic stroke. Brain Research 1623, 166-173.

Sakanaka, M., Wen, T. C., Matsuda, S., Masuda, S., Morishita, E., Nagao, M. and Sasaki, R. (1998) In vivo evidence that erythropoietin protects neurons from ischemic damage. Proceedings of the National Academy of Sciences of the United States of America 95, 4635-4640.

Sargin, D., El-Kordi, A., Agarwal, A., Muller, M., Wojcik, S. M., Hassouna, I., Sperling, S., Nave, K. A. and Ehrenreich, H. (2011) Expression of constitutively active erythropoietin receptor in pyramidal neurons of cortex and hippocampus boosts higher cognitive functions in mice. BMC Biology 9, 27.

Sargin, D., Hassouna, I., Sperling, S., Siren, A. L. and Ehrenreich, H. (2009) Uncoupling of neurodegeneration and gliosis in a murine model of juvenile cortical lesion. Glia 57, 693-702.

Schneider Gasser, E. M., Elliot-Portal, E., Arias-Reyes, C., LosantosRamos, K., Khalid, K., Ogunshola, O. and Soliz, J. (2019) Developmental expression patterns of erythropoietin and its receptor in mouse brainstem respiratory regions. Respiratory Physiology and Neurobiology 267, 12-19.

Shingo, T., Sorokan, S. T., Shimazaki, T. and Weiss, S. (2001) Erythropoietin regulates the in vitro and in vivo production of neuronal progenitors by mammalian forebrain neural stem cells. Journal of Neuroscience 21, 9733-9743.

Simon, F., Scheuerle, A., Groger, M., Vcelar, B., McCook, O., Moller, P., Georgieff, M., Calzia, E., Radermacher, P. and Schelzig, H. (2011) Comparison of carbamylated erythropoietin-FC fusion protein and recombinant human erythropoietin during porcine aortic balloon occlusion-induced spinal cord ischemia/reperfusion injury. Intensive Care Medicine 37, 1525-1533.

Simon, F. H., Erhart, P., Vcelar, B., Scheuerle, A., Schelzig, H. and Oberhuber, A. (2016) Erythropoietin preconditioning improves clinical and histologic outcome in an acute spinal cord ischemia and reperfusion rabbit model. Journal of Vascular Surgery 64, 1797-1804.

Smith, K. and Semenov, M. V. (2019) The impact of age on number and distribution of proliferating cells in subgranular zone in adult mouse brain. IBRO Reports 6, 18-30.

Socolovsky, M., Nam, H., Fleming, M. D., Haase, V. H., Brugnara, C. and Lodish, H. F. (2001) Ineffective erythropoiesis in Stat5a(-/-)5b(-/-) mice due to decreased survival of early erythroblasts. Blood 98, 3261-3273.

Sollinger, C., Lillis, J., Malik, J., Getman, M., Proschel, C. and Steiner, L. (2017) Erythropoietin signaling regulates key epigenetic and transcription networks in fetal neural progenitor cells. Scientific Reports 7 , 14381.

Sorrells, S. F., Paredes, M. F., Cebrian-Silla, A., Sandoval, K., Qi, D., Kelley, K. W., James, D., Mayer, S., Chang, J., Auguste, K. I., Chang, E. F., Gutierrez, A. J., Kriegstein, A. R., Mathern, G. W., Oldham, M. C., Huang, E. J., Garcia-Verdugo, J. M., Yang, Z. and Alvarez-Buylla, A. (2018) Human hippocampal neurogenesis drops sharply in children to undetectable levels in adults. Nature 555, 377-381.

Spalding, K. L., Bergmann, O., Alkass, K., Bernard, S., Salehpour, M., 
Huttner, H. B., Bostrom, E., Westerlund, I., Vial, C., Buchholz, B. A., Possnert, G., Mash, D. C., Druid, H. and Frisen, J. (2013) Dynamics of hippocampal neurogenesis in adult humans. Cell 153, 1219-1227.

Sugawa, M., Sakurai, Y., Ishikawa-Ieda, Y., Suzuki, H. and Asou, H. (2002) Effects of erythropoietin on glial cell development; oligodendrocyte maturation and astrocyte proliferation. Neuroscience Research 44, 391-403.

Suzuki, N., Suwabe, N., Ohneda, O., Obara, N., Imagawa, S., Pan, X., Motohashi, H. and Yamamoto, M. (2003) Identification and characterization of 2 types of erythroid progenitors that express GATA-1 at distinct levels. Blood 102, 3575-3583.

Takei, Y. (2019) Age-dependent decline in neurogenesis of the hippocampus and extracellular nucleotides. Human Cell 32, 88-94.

Tiwari, N. K., Sathyanesan, M., Schweinle, W. and Newton, S. S. (2019) Carbamoylated erythropoietin induces a neurotrophic gene profile in neuronal cells. Progress in Neuro-Psychopharmacology and Biological Psychiatry 88, 132-141.

Tsai, P. T., Ohab, J. J., Kertesz, N., Groszer, M., Matter, C., Gao, J., Liu, X., Wu, H. and Carmichael, S. T. (2006) A critical role of erythropoietin receptor in neurogenesis and post-stroke recovery. Journal of Neuroscience 26, 1269-1274.

Tsai, T. H., Lu, C. H., Wallace, C. G., Chang, W. N., Chen, S. F., Huang, C. R., Tsai, N. W., Lan, M. Y., Sung, P. H., Liu, C. F. and Yip, H. K. (2015) Erythropoietin improves long-term neurological outcome in acute ischemic stroke patients: a randomized, prospective, placebo-controlled clinical trial. Critical Care 19, 49.

Tuttolomondo, A., Pecoraro, R., Arnao, V., Maugeri, R., Iacopino, D. G. and Pinto, A. (2015) Developing drug strategies for the neuroprotective treatment of acute ischemic stroke. Expert Review Neurotherapeutics 15, 1271-1284

Villa, P., Bigini, P., Mennini, T., Agnello, D., Laragione, T., Cagnotto, A., Viviani, B., Marinovich, M., Cerami, A., Coleman, T. R., Brines, M. and Ghezzi, P. (2003) Erythropoietin selectively attenuates cytokine production and inflammation in cerebral ischemia by targeting neuronal apoptosis. Journal of Experimental Medicine 198, 971-975.

Wagner, K. U., Claudio, E., Rucker, E. B., 3rd, Riedlinger, G., Broussard, C., Schwartzberg, P. L., Siebenlist, U. and Hennighausen, L. (2000) Conditional deletion of the Bcl-x gene from erythroid cells results in hemolytic anemia and profound splenomegaly. Development 127, 49494958

Wang, L., Zhang, Z. G., Gregg, S. R., Zhang, R. L., Jiao, Z., LeTourneau, Y., Liu, X., Feng, Y., Gerwien, J., Torup, L., Leist, M., Noguchi, C. T., Chen, Z. Y. and Chopp, M. (2007) The Sonic hedgehog pathway mediates carbamylated erythropoietin-enhanced proliferation and differentiation of adult neural progenitor cells. Journal of Biological Chemistry 282, 32462-32470.

Wang, L., Zhang, Z. G., Zhang, R. L., Gregg, S. R., Hozeska-Solgot, A., LeTourneau, Y., Wang, Y. and Chopp, M. (2006) Matrix metalloproteinase 2 (MMP2) and MMP9 secreted by erythropoietin-activated endothelial cells promote neural progenitor cell migration. Journal of Neuroscience 26, 5996-6003.

Wang, R., Li, J., Duan, Y., Tao, Z., Zhao, H. and Luo, Y. (2017) Effects of erythropoietin on gliogenesis during cerebral ischemic/reperfusion recovery in adult mice. Aging and Disease 8, 410-419.

Wang, R., Wu, X., Liang, J., Qi, Z., Liu, X., Min, L., Ji, X., Luo, Y. and Zhao, H. (2015) Intra-artery infusion of recombinant human erythropoietin reduces blood-brain barrier disruption in rats following cerebral ischemia and reperfusion. International Journal of Neuroscience 125, 693-702.

Wang, Y., Cooke, M. J., Sachewsky, N., Morshead, C. M. and Shoichet, M. S. (2013) Bioengineered sequential growth factor delivery stimulates brain tissue regeneration after stroke. Journal of Controlled Release 172, 1-11.

Wang, Y., Yao, M., Zhou, C., Dong, D., Jiang, Y., Wei, G. and Cui, X. (2010) Erythropoietin promotes spinal cord-derived neural progenitor cell proliferation by regulating cell cycle. Neuroscience 167, 750-757.

Wiltrout, C., Lang, B., Yan, Y., Dempsey, R. J. and Vemuganti, R. (2007) Repairing brain after stroke: a review on post-ischemic neurogenesis. Neurochemistry International 50, 1028-1041.
Wright, G. L., Hanlon, P., Amin, K., Steenbergen, C., Murphy, E. and Arcasoy, M. O. (2004) Erythropoietin receptor expression in adult rat cardiomyocytes is associated with an acute cardioprotective effect for recombinant erythropoietin during ischemia-reperfusion injury. The FASEB Journal 18, 1031-1033.

Wu, Y. W., Mathur, A. M., Chang, T., McKinstry, R. C., Mulkey, S. B., Mayock, D. E., Van Meurs, K. P., Rogers, E. E., Gonzalez, F. F., Comstock, B. A., Juul, S. E., Msall, M. E., Bonifacio, S. L., Glass, H. C., Massaro, A. N., Dong, L., Tan, K. W., Heagerty, P. J. and Ballard, R. A. (2016) High-dose erythropoietin and hypothermia for hypoxic-ischemic encephalopathy: a phase II trial. Pediatrics 137.

Xiong, Y., Mahmood, A., Zhang, Y., Meng, Y., Zhang, Z. G., Qu, C., Sager, T. N. and Chopp, M. (2011) Effects of posttraumatic carbamylated erythropoietin therapy on reducing lesion volume and hippocampal cell loss, enhancing angiogenesis and neurogenesis, and improving functional outcome in rats following traumatic brain injury. Journal of Neurosurgery 114, 549-559.

Yu, X., Shacka, J. J., Eells, J. B., Suarez-Quian, C., Przygodzki, R. M., Beleslin-Cokic, B., Lin, C. S., Nikodem, V. M., Hempstead, B., Flanders, K. C., Costantini, F. and Noguchi, C. T. (2002) Erythropoietin receptor signalling is required for normal brain development. Development 129, 505-516.

Yan, F., Zhang, M., Meng, Y., Li, H., Yu, L., Fu, X., Tang, Y. and Jiang, C. (2016) Erythropoietin improves hypoxic-ischemic encephalopathy in neonatal rats after short-term anoxia by enhancing angiogenesis. Brain Research 1651, 104-113.

Zechariah, A., ElAli, A. and Hermann, D. M. (2010) Combination of tissueplasminogen activator with erythropoietin induces blood-brain barrier permeability, extracellular matrix disaggregation, and DNA fragmentation after focal cerebral ischemia in mice. Stroke 41, 1008-1012.

Zhang, H., Fang, X., Huang, D., Luo, Q., Zheng, M., Wang, K., Cao, L. and Yin, Z. (2018) Erythropoietin signaling increases neurogenesis and oligodendrogenesis of endogenous neural stem cells following spinal cord injury both in vivo and in vitro. Molecular Medicine Reports 17, 264-272.

Zhang, L., Chopp, M., Zhang, R. L., Wang, L., Zhang, J., Wang, Y., Toh, Y., Santra, M., Lu, M. and Zhang, Z. G. (2010) Erythropoietin amplifies stroke-induced oligodendrogenesis in the rat. PLoS One 5, e11016.

Zhang, R. L., Zhang, Z. G. and Chopp, M. (2008) Ischemic stroke and neurogenesis in the subventricular zone. Neuropharmacology 55, 345352.

Zhang, R. L., Zhang, Z. G., Lu, M., Wang, Y., Yang, J. J. and Chopp, M. (2006) Reduction of the cell cycle length by decreasing G1 phase and cell cycle reentry expand neuronal progenitor cells in the subventricular zone of adult rat after stroke. Journal of Cerebral Blood Flow and Metabolism 26, 857-863.

Zhang, S. J., Wang, R. L., Zhao, H. P., Tao, Z., Li, J. C., Ju, F., Han, Z. P., Ma, Q. F., Liu, P., Ma, S. B., Cao, G. D. and Luo, Y. M. (2019) MEPO promotes neurogenesis and angiogenesis but suppresses gliogenesis in mice with acute ischemic stroke. European Journal of Pharmacology 849, $1-10$.

Zhao, C., Teng, E. M., Summers, R. G., Jr., Ming, G. L. and Gage, F. H. (2006a) Distinct morphological stages of dentate granule neuron maturation in the adult mouse hippocampus. Journal of Neuroscience 26, 3-11.

Zhao, H., Wang, R., Wu, X., Liang, J., Qi, Z., Liu, X., Min, L., Ji, X. and Luo, Y. (2015) Erythropoietin delivered via intra-arterial infusion reduces endoplasmic reticulum stress in brain microvessels of rats following cerebral ischemia and reperfusion. Journal of Neuroimmune Pharmacology 10, 153-161.

Zhao, W., Kitidis, C., Fleming, M. D., Lodish, H. F. and Ghaffari, S. (2006b) Erythropoietin stimulates phosphorylation and activation of GATA-1 via the PI3-kinase/AKT signaling pathway. Blood 107, 907915.

Zsokova, E., Ilkovicova, L., Kimakova, P., Feckova, B. and Solar, P. (2019) Erythropoietin receptor induces a paclitaxel resistance phenotype in mammary adenocarcinoma cells. Oncology Reports 42, 11491160 . 